\title{
Erratum to: A preliminary double-blind, placebo-controlled randomized study of baclofen effects in alcoholic smokers
}

\author{
Lorenzo Leggio $^{1,2,3}$ • William H. Zywiak ${ }^{4,5,6}$ • Steven M. Edwards ${ }^{7}$. Jennifer W. Tidey ${ }^{6}$. \\ Robert M. Swift ${ }^{6,8,9} \cdot$ George A. Kenna $^{6}$
}

Published online: 26 March 2015

(C) Springer-Verlag Berlin Heidelberg 2015

\section{Erratum to: Psychopharmacology \\ DOI 10.1007/s00213-014-3652-9}

The original version of this manuscript contained a mistake in the text. The sentence 'BACL significantly reduced the $\%$ days of abstinence from alcohol-tobacco co-use (BACL, 12.1 \pm 2.0 vs. PLA, 3.5 $\pm 2.2(\mathrm{M} \pm \mathrm{SE}) ; \mathrm{F}(1,197.6)=8.27, \mathrm{p}=0.004$; Fig. 1a).' should read 'BACL significantly increased the $\%$ days of abstinence from alcohol-tobacco co-use (BACL, $12.1 \pm 2.0$ vs. PLA, $3.5 \pm 2.2(\mathrm{M} \pm \mathrm{SE}) ; \mathrm{F}(1,197.6)=8.27$, $\mathrm{p}=0.004$; Fig. 1a).'

The online version of the original article can be found at http://dx.doi.org/ 10.1007/s00213-014-3652-9.

\section{Lorenzo Leggio}

lorenzo.leggio@nih.gov

1 Section on Clinical Psychoneuroendocrinology and Neuropsychopharmacology, Laboratory of Clinical and Translational Studies, National Institute on Alcohol Abuse and Alcoholism, National Institutes of Health, 10 Center Drive (10CRC/15330) MSC 1108; Room 1-5429, Bethesda, MD 20892-1108, USA

2 Intramural Research Program, National Institute on Drug Abuse, National Institutes of Health, Baltimore, MD, USA

3 Department of Behavioral and Social Sciences, Center for Alcohol and Addiction Studies, Brown University, Providence, RI, USA

4 Decision Sciences Institute, P.I.R.E, Pawtucket, RI, USA

5 Butler Hospital, Providence, RI, USA

6 Department of Psychiatry and Human Behavior, Center for Alcohol and Addiction Studies, Brown University, Providence, RI, USA

7 Department of Psychology, University of Nebraska-Lincoln, Lincoln, NE, USA

8 Veterans Affairs Medical Center, Providence, RI, USA

9 Roger Williams Medical Center, Providence, RI, USA 